\title{
The relationship between self-reported history of endodontic therapy and coronary heart disease in the Atherosclerosis Risk in Communities Study
}

\author{
Daniel J. Caplan, DDS, PhD [professor and the chair], \\ Department of Preventive and Community Dentistry, College of Dentistry, University of lowa, lowa \\ City, lowa 52242
}

James S. Pankow, PhD, MPH [associate professor],

Department of Epidemiology, University of Minnesota, Minneapolis

Jianwen Cai, PhD [professor],

Department of Biostatistics, University of North Carolina, Chapel Hill

Steven Offenbacher, DDS, PhD, MS [OraPharma Distinguished Professor of Periodontal Medicine and the director], and

Center for Oral and Systemic Diseases, North Carolina Oral Health Institute, Durham

James D. Beck, PhD [Distinguished Professor]

Department of Dental Ecology, and the associate dean for research, University of North Carolina, Chapel Hill

\begin{abstract}
Background-Results from numerous studies have suggested links between periodontal disease and coronary heart disease (CHD), but endodontic disease has not been studied extensively in this regard.

Methods-The authors evaluated the relationship between self-reported history of endodontic therapy (ET) and prevalent CHD in the Atherosclerosis Risk in Communities (ARIC) Study, aprospective epidemiologic study sponsored by the National Heart, Lung, and Blood Institute. The authors used multivariable logistic regres-sionto analyze data obtained from oral health questionnaires, medical evaluations and clinical dental examinations.

Results-Of 6,651 participants analyzed, 50.4 percent reported never having had ET; 21.5 percent reported having had ET one time; and 28.0 percent reported having had ET two or more times. Final multivariable regression models indicated that among participants with 25 or more teeth, those reporting having had ET two or more times had 1.62 (95 percent confidence interval [CI], 1.04-2.53) times the odds of prevalent CHD compared with those reporting never having had ET. Among participants with 24 or fewer teeth, no significant differences in CHD prevalence were observed among groups regardless of their history of ET.
\end{abstract}

Conclusions-Among participants with 25 or more teeth, those with a greater self-reported history of ET were more likely to have CHD than were those reporting no history of ET.

(C) 2009 American Dental Association. All rights reserved.

“dan-caplan@uiowa.edu“. Address reprint requests to Dr. Caplan..

Disclosure. None of the authors reported any disclosures. 
Clinical Implications-More accurate epidemiologic quantification of endodontic infection and inflammation is required before definitive conclusions can be made about potential relationships between endodontic disease and CHD.

\title{
Keywords
}

Endodontics; epidemiology; root canal

\begin{abstract}
Although results from numerous studies have showed associations between periodontal disease and cardiovascular conditions, ${ }^{1-4}$ endodontic disease has not been studied extensively in this regard. In response to gram-negative anaerobic bacteria found in periodontal disease, certain people may produce an overabundance of localized or systemic inflammatory mediators, or both, which might contribute to vascular damage and cardiovascular events. ${ }^{5-7}$ Endodontic infections could be related to cardiovascular conditions in an analogous fashion, given the predominance of gram-negative anaerobes associated with endodontic infections that include periodontal pathogens ${ }^{8,9}$ and evidence of cytokine production in inflamed pulp and periapical granulomatous tissues. ${ }^{10-12}$
\end{abstract}

Endodontic inflammation occurs after bacteria or their byproducts enter a tooth's pulp chamber. Acute endodontic inflammation generally manifests as a toothache, whereas chronic endodontic inflammation can remain asymptomatic for months or years. To treat both acute and chronic endodontic inflammation, dentists can perform endodontic therapy (ET), which is intended to eradicate bacteria and their byproducts from the root canal system and fill the prepared space with inert, radiopaque filling material.

Epidemiologic assessment of current and past periodontal inflammation can occur clinically through measurement of periodontal pockets, attachment loss or both, but endodontic disease must be evaluated through observation of periapical bony lesions on radiographs (indicative of chronic endodontic inflammation) or of radiopaque material in the root canal system (indicative of a history of ET). ${ }^{13}$ However, epidemiologic clinical examiners generally do not have access to participants' radiographs. In the absence of radiographic information, one way to estimate history of endodontic disease is through participants' self-reports of endodontic treatment.

We conducted a cross-sectional study to evaluate the relationship between self-reported history of ET and prevalent coronary heart disease (CHD) among dentate participants in the Atherosclerosis Risk in Communities (ARIC) Study. The ARIC Study is an ongoing longitudinal population-based epidemiologic investigation sponsored by the National Heart, Lung, and Blood Institute that was designed to assess determinants of atherosclerosis and to describe its effect on community mortality and morbidity. Our hypothesis was that odds of prevalent CHD would be higher among participants with a greater self-reported history of ET.

\section{METHODS}

The ARIC Study has been conducted at four U.S. sites: Forsyth County, N.C.; Jackson, Miss.; suburban Minneapolis; and Washington County, Md. We obtained data used in our crosssectional analysis from the ARIC Study dental component (conducted during ARIC Study visit 4, which took place from 1996 through 1998), at which time participants completed oral health questionnaires and underwent clinical dental examinations that involved no radiographic assessment. The institutional review board at the University of North Carolina approved the study before its commencement.

Study personnel examined 15,792 participants at the initial ARIC Study visit (1987-1989), and 11,656 of these completed visit 4 (1996-1998). Of these, 3,372 were ineligible for a dental 
examination (1,651 had no teeth, 70 underwent no dental screening, 1,621 were excluded for medical reasons that contraindicated periodontal probing, and 30 were excluded for unknown reasons), leaving 8,284 eligible participants. Of these, 1,353 did not undergo a dental examination ( 767 refused, 550 agreed to be examined but were not, and 36 were excluded for other reasons), leaving 6,931 dental examinees. Finally, 36 and 244 participants did not have data for the main exposure and outcome variables, respectively, leaving 6,651 participants.

The study outcome was prevalent CHD as described by Beck and colleagues. ${ }^{14}$ The ARIC Study investigators collected data regarding self-reported physician-diagnosed CHD from participants before they enrolled in the study (1987-1989) and abstracted hospital records yearly for all hospitalizations reported by cohort members, followed by validation of discharge diagnoses according to standardized criteria. ${ }^{15}$ In addition, the ARIC Study investigators considered any participant who had undergone coronary revascularization procedures or had unequivocal electrocardiographic signs of myocardial infarction before the dental visit to have prevalent CHD. We did not include in our analyses any CHD events that occurred after the dental examination.

We determined the main exposure variable from participants' responses to two questions: "Have you ever had root canal therapy?" and "If so, have you had more than one?" Covariates we considered in the analyses were sociodemographic, dental and medical variables often used in ARIC dental studies addressing associations between periodontal conditions and systemic disease, ${ }^{16,17}$ plus other variables reflective of dental care use or caries history. Specifically, the sociodemographic factors were age (in years, at visit 4), sex, race, ARIC Study field center, income (less than or equal to $\$ 35,000$ per year, more than $\$ 35,000$ per year), education (some high school, high school diploma, bachelor's or graduate degree), usual source of medical care (private physician, health maintenance organization [HMO], regular clinic, hospital emergency department, walk-in clinic), and usual medical care payment mechanism (health insurance, Medicare, Medicaid). Dental variables were numbers of teeth, carious coronal and root surfaces, and filled coronal and root surfaces. We also assessed extents of periodontal attachment loss of 4 millimeters or greater and periodontal pocket depth of $5 \mathrm{~mm}$ or greater (extents calculated as the number of sites at or above the given threshold divided by the number of measured sites, then multiplied by 100). Medical factors were body mass index (kilograms per square meter); diabetes (fasting blood glucose level of $\geq 126$ milligrams per deciliter, nonfasting blood glucose level of $\geq 200 \mathrm{mg} / \mathrm{dL}$, use of diabetes medication or self-reported physician's diagnosis of diabetes); hypertension (systolic blood pressure $\geq 140 \mathrm{~mm}$ of mercury [Hg] or diastolic blood pressure $\geq 90 \mathrm{~mm} / \mathrm{Hg}$ or self-reported use of antihypertensive medications in the preceding two weeks ${ }^{18}$ ); pack-year smoking history; fasting levels of lowdensity lipoprotein cholesterol, high-density lipoprotein (HDL) cholesterol and triglycerides $(\mathrm{mg} / \mathrm{dL})$; and use of aspirin or cholesterol-lowering medications.

We anticipated a priori that those reporting having had no ET would consist of two highly disparate subgroups: those who had good oral health and never needed ET, and those who had poor oral health and needed ET but never had received it. In contrast, we expected those reporting a history of ET to be a relatively homogenous group. Thus, we dichotomized the variable "number of teeth" at the median and used it in the analyses as an interaction term with self-reported ET. We did not hypothesize a priori or evaluate any other interaction terms.

We generated univariate and bivariate frequency distributions and examined stratified frequency tables, and we tested for significant differences among comparison groups using analysis of variance (for continuous variables) and extended Mantel-Haenszel $\chi^{2}$ tests (for categorical variables). We used multivariable logistic regression to develop explanatory models comparing odds of prevalent CHD across exposure categories, controlling for potential confounding or stratification variables. First, we developed an initial model that contained only 
the main exposure variable and the interaction term. Second, we generated a full model that included these terms plus all covariates mentioned earlier. Finally, we generated a final model containing fewer variables by deleting covariates from the full model. (We deleted a covariate if its removal elicited a change of less than .05 to every odds ratio [OR] that involved the main exposure variable; otherwise, we retained it.)

\section{RESULTS}

Among the 6,651 participants, 395 (5.9 percent) had prevalent CHD, and the median number of teeth was 24 . We categorized participants into three ET groups:

group 0: 3,356 participants (50.4 percent), including 3,311 (49.8 percent) who reported never having had ET and 45 ( 0.7 percent) who reported uncertainty about having had ET;

group 1: 1,432 participants (21.5 percent), including 1,363 (20.5 percent) who reported having had ET exactly once and 69 (1.0 percent) who reported uncertainty about having had ET more than once;

group 2: 1,863 participants (28.0 percent), all of whom reported having had ET twice or more.

Table 1 presents sociodemographic data across main exposure categories and "number of teeth" strata. In both strata, group 0 participants tended to be of lower socioeconomic status. Education and income were directly related to self-reported history of ET, as was the proportion of white participants. In addition, group 0 participants were less likely to use HMOs as their usual source of medical care or to use health insurance for their usual medical care payment mechanism.

Table 2 (page 1008) presents dental and medical data. In both strata, group 0 participants tended to have worse measures of oral health, including more carious coronal surfaces and greater extents of attachment loss and pocket depth. In addition, self-reported history of ET was directly associated with mean number of crowns. Group 0 participants with 24 or fewer teeth had the highest CHD prevalence ( 7.3 percent), followed by group 2 participants in both strata. Group 0 participants with 25 or more teeth had the lowest CHD prevalence (4.4 percent). Among those with 24 or fewer teeth, more group 0 participants had diabetes and hypertension and more were obese than were participants in groups 1 and 2, but they had better HDL cholesterol and triglyceride profiles. In both strata, group 2 participants had pack-year smoking histories greater than those of participants in the other two groups.

Table 3 (page 1009) presents findings from the multivariable logistic regression models, with the reference group being "group 0 and 25 or more teeth." The interaction term between selfreported history of ET and number of teeth was significant, necessitating five terms in the initial model. Controlling for all covariates increased the relevant ORs for those with 25 or more teeth and either decreased or maintained the relevant ORs for those with 24 or fewer teeth. In the final model, among those with 25 or more teeth, group 2 participants had significantly higher odds of prevalent CHD than did group 0 participants (OR, 1.62; 95 percent confidence interval [CI], 1.04-2.53). Group 1 participants had odds that were not significantly higher than those of group 0 participants (OR, 1.37; 95 percent CI, 0.83-2.26).

Table 4 (page 1010) facilitates interpretation of ORs among participants with 24 or fewer teeth. The top section presents the five relevant ORs from the final model in Table 3, while the bottom section presents this same information but using group 0 participants with 24 or fewer teeth as the reference. Among those with 24 or fewer teeth, neither group 1 nor group 2 participants had significantly different odds of prevalent CHD compared with group 0 participants (ORs, 0.67 and 1.12 , respectively). 
We obtained similar results when we generated initial models that included the same participants as did the other models. Exclusion of the 114 participants (1.7 percent) of participants who reported uncertainty about their history of ET had no substantial influence on any estimates (results not shown).

\section{DISCUSSION}

Studies involving potential relationships between periodontal disease and CHD are plentiful, but few published investigations focus on potential links between endodontic disease and CHD. Mechanisms linking endodontic disease to CHD might be similar to those hypothesized for associations between periodontal disease and CHD, in which a localized inflammatory response to bacterial infection leads to release of cytokines into the systemic circulation and to subsequent deleterious vascular effects. ${ }^{3,4}$ Links between endodontic inflammation and cardiovascular outcomes are biologically plausible, considering the predominance of gramnegative anaerobes associated with endodontic infections, ${ }^{9,19,20}$ evidence of cytokine production in inflamed pulp and periapical granulomatous tissues, ${ }^{11,12,21}$ and the fact that elevated systemic levels of inflammatory mediators have been observed in patients undergoing endodontic treatment. ${ }^{22,23}$

In our study, among participants with 25 or more teeth, those reporting having undergone ET two or more times had significantly greater odds of prevalent CHD compared with those who reported having had no ET, while among participants with 24 or fewer teeth, we observed no significant differences between subgroups (Table 4). For several reasons, self-reported history of ET is an imperfect approximation of cumulative endodontic disease and thus potentially could lead to bias.

On many occasions, ET is performed to treat acute (rather than chronic) endodontic inflammation, but hypotheses proposed to explain potential links between periodontal disease and CHD are based on only chronic inflammation.

ET sometimes is performed for restorative rather than endodontic reasons, ${ }^{24}$ and teeth with normal pulps would not contribute substantially to the cumulative endodontic inflammatory burden.

Misclassification of history of ET easily could occur (for example, by participants' confusing ET with other procedures).

Lack of history of ET does not necessarily imply absence of endodontic inflammation, because some endodontically involved teeth are extracted and others remain asymptomatic and untreated.

ET represents treatment rather than disease, so a simple count of ET experiences implies neither outright elimination nor persistence of endodontic disease after therapy. Authors of one recent systematic review reported weighted pooled "endodontic success rates" from 68 to 85 percent, with various factors (such as extension and density of root filling material) being related to success. ${ }^{25}$

Despite these important sources of potential error, our findings were statistically significant in the stratum of participants with 25 or more teeth when we compared subgroups reporting the highest versus the lowest ET history. It is possible that we saw no relationship in the stratum of participants with 24 or fewer teeth because a greater number of missing teeth increases the likelihood that many were extracted for reasons other than caries (such as periodontal disease or prosthetic treatment).

We could not validate history of ET because no radiographs were taken during the ARIC Study, but even had they been, teeth could have been treated with ET and extracted before data 
collection. We found only one published study focusing on validity of self-reported history of ET. Pitiphat and colleagues ${ }^{26}$ asked 58 adult first-time patients at the Harvard School of Dental Medicine student dental clinic, "How many of your permanent teeth in your mouth now have [undergone] endodontic therapy?" The authors reported a positive predictive value of 86 percent and a negative predictive value of 95 percent, but those figures likely are higher than would be expected in our study because the participants were a mean 41 years of age, or 20 years younger than that of our participants-and, thus, more likely to have undergone fewer ET procedures and to remember them accurately. The results of the two studies also are not exactly comparable, because Pitiphat and colleagues ${ }^{26}$ asked participants about the number of endodontically treated teeth currently in the mouth, rather than the cumulative number of ET procedures they had undergone.

Finally, although we could not validate history of ET, some indirect validation of that exposure could be inferred. In general, ET should be more common among those of higher socioeconomic status because ET is relatively costly; those reporting a greater history of ET should tend to have more crowns, because crowns often are placed on teeth after ET is completed and because ET often is performed on crowned teeth. Our findings were consistent with these concepts: education, income levels and mean number of crowns increased with greater self-reported history of ET in both strata (Table 1 and Table 2).

Although few studies in this area have been published, our findings were consistent with those of Joshipura and colleagues,${ }^{27}$ who observed a greater CHD incidence among men with a positive self-reported history of ET in the Health Professionals Follow-up Study, and with those of Caplan and colleagues, ${ }^{28}$ who observed a significant association between lesions of endodontic origin and time to CHD diagnosis among men participating in the Veterans Affairs Dental Longitudinal Study. Conversely, Frisk and colleagues ${ }^{29}$ did not find a significant relationship between number of root-filled teeth and prevalent CHD in a population-based study of Swedish women.

We found a significant association between self-reported history of ET and prevalent CHD among participants with 25 or more teeth; however, our study design precluded validation of the main exposure variable. Even had that variable been validated, ET represents treatment of endodontic inflammation rather than the inflammatory condition itself, so if one observed an association, it still would be impossible (using the study design described here) to disentangle the treatment from the disease. In addition, our study's design precluded ascertainment of the timing of ET procedures as they related to the timing of CHD diagnoses. Because the epidemiologic study of potential relationships between endodontic disease and CHD is in its infancy, future investigators should incorporate longitudinal designs, use radiographic information and attempt to gather more direct measures of endodontic infection and inflammation.

\section{CONCLUSIONS}

Among ARIC Study participants with 25 or more teeth, those with a greater self-reported history of ET were more likely to have CHD than were those reporting no history of ET. More accurate epidemiologic quantification of endodontic infection and inflammation is required before definitive conclusions can be made about potential relationships between endodontic disease and CHD. 


\section{ABBREVIATION KEY}

ARIC, Atherosclerosis Risk in Communities; CHD, Coronary heart disease; ET, Endodontic therapy; HDL, High-density lipoprotein; Hg, Mercury; HMO, Health maintenance organization.

\section{Acknowledgments}

The Atherosclerosis Risk in Communities Study is carried out as a collaborative study supported by National Heart, Lung, and Blood Institute contracts N01-HC-55015, N01-HC-55016, N01-HC-55018. N01-HC-55019, N01HC-55020, N01-HC-55021 and N01-HC-55022. The collection and analysis of dental data for this article were supported by National Institute of Dental and Craniofacial Research grants DE13807-01A1 and DE11551.

The authors thank the staff of and participants in the Atherosclerosis Risk in Communities Study for their important contributions.

\section{References}

1. Janket SJ, Baird AE, Chuang SK, Jones JA. Meta-analysis of periodontal disease and risk of coronary heart disease and stroke. Oral Surg Oral Med Oral Pathol Oral Radiol Endod 2003;95(5):559-569. [PubMed: 12738947]

2. Grau AJ, Becher H, Ziegler CM, et al. Periodontal disease as a risk factor for ischemic stroke. Stroke 2004;35(2):496-501. [PubMed: 14707235]

3. Beck J, Garcia R, Heiss G, Vokonas PS, Offenbacher S. Periodontal disease and cardiovascular disease. J Periodontol 1996;67(10 suppl):1123-1137. [PubMed: 8910831]

4. Dietrich T, Jimenez M, Krall Kaye EA, Vokonas PS, Garcia RI. Age-dependent associations between chronic periodontitis/edentulism and risk of coronary heart disease. Circulation 2008;117(13):16681674. [PubMed: 18362228]

5. Offenbacher S, Elter JR, Lin D, Beck JD. Evidence for periodontitis as a tertiary vascular infection. J Int Acad Periodontol 2005;7(2):39-48. [PubMed: 15912923]

6. Offenbacher S, Beck JD. A perspective on the potential cardioprotective benefits of periodontal therapy. Am Heart J 2005;149(6):950-954. [PubMed: 15976771]

7. Offenbacher S, Madianos PN, Champagne CM, et al. Periodontitis-atherosclerosis syndrome: an expanded model of pathogenesis. J Periodontal Res 1999;34(7):346-352. [PubMed: 10685359]

8. Noiri Y, Li L, Ebisu S. The localization of periodontal-disease-associated bacteria in human periodontal pockets. J Dent Res 2001;80(10):1930-1934. [PubMed: 11706954]

9. Sundqvist G. Ecology of the root canal flora. J Endod 1992;18(9):427-430. [PubMed: 9796509]

10. Gamonal J, Acevedo A, Bascones A, Jorge O, Silva A. Levels of interleukin-1 beta, -8 , and -10 and RANTES in gingival crevicular fluid and cell populations in adult periodontitis patients and the effect of periodontal treatment. J Periodontol 2000;71(10):1535-1545. [PubMed: 11063385]

11. Miller GA, DeMayo T, Hutter JW. Production of interleukin-1 by polymorphonuclear leukocytes resident in periradicular tissue. J Endod 1996;22(7):346-351. [PubMed: 8935058]

12. Barkhordar RA, Hayashi C, Hussain MZ. Detection of interleukin-6 in human dental pulp and periapical lesions. Endod Dent Traumatol 1999;15(1):26-27. [PubMed: 10219150]

13. Caplan DJ. Epidemiologic issues in studies of association between apical periodontitis and systemic health. Endod Topics 2004;8:15-35.

14. Beck JD, Eke P, Heiss G, et al. Periodontal disease and coronary heart disease: a reappraisal of the exposure. Circulation 2005;112(1):19-24. [PubMed: 15983248]

15. Rosamond WD, Chambless LE, Folsom AR, et al. Trends in the incidence of myocardial infarction and in mortality due to coronary heart disease, 1987 to 1994. N Engl J Med 1998;339(13):861-867. [PubMed: 9744969]

16. Elter JR, Offenbacher S, Toole JF, Beck JD. Relationship of periodontal disease and edentulism to stroke/TIA. J Dent Res 2003;82(12):998-1001. [PubMed: 14630902] 
17. Beck JD, Elter JR, Heiss G, Couper D, Mauriello SM, Offenbacher S. Relationship of periodontal disease to carotid artery intima-media wall thickness: the atherosclerosis risk in communities (ARIC) study. Arterioscler Thromb Vasc Biol 2001;21(11):1816-1822. [PubMed: 11701471]

18. Atherosclerosis Risk in Communities Study Investigators. ARIC Manual of Operations. No. 11: Sitting blood pressure. Version 1.0. Bethesda, Md.: National Heart, Lung, and Blood Institute of the National Institutes of Health; 1987.

19. Baumgartner JC. Microbiologic and pathologic aspects of endodontics. Curr Opin Dent 1991;1(6): 737-743. [PubMed: 1807476]

20. Sundqvist G. Associations between microbial species in dental root canal infections. Oral Microbiol Immunol 1992;7(5):257-262. [PubMed: 1494447]

21. Kuo ML, Lamster IB, Hasselgren G. Host mediators in endodontic exudates, part 1: indicators of inflammation and humoral immunity. J Endod 1998;24(9):598-603. [PubMed: 9922748]

22. Márton I, Kiss C, Balla G, Szabó T, Karmazsin L. Acute phase proteins in patients with chronic periapical granuloma before and after surgical treatment. Oral Microbiol Immunol 1988;3(2):95-96. [PubMed: 3268759]

23. Marton IJ, Kiss C. Influence of surgical treatment of periapical lesions on serum and blood levels of inflammatory mediators. Int Endod J 1992;25(5):229-233. [PubMed: 1291518]

24. Caplan DJ, Weintraub JA. Factors related to loss of root canal filled teeth. J Public Health Dent 1997;57(1):31-39. [PubMed: 9150061]

25. Ng YL, Mann V, Rahbaran S, Lewsey J, Gulabivala K. Outcome of primary root canal treatment: systematic review of the literature, part 1 -effects of study characteristics on probability of success. Int Endod J 2007;40(12):921-939. [PubMed: 17931389]

26. Pitiphat W, Garcia RI, Douglass CW, Joshipura KJ. Validation of self-reported oral health measures. J Public Health Dent 2002;62(2):122-128. [PubMed: 11989207]

27. Joshipura KJ, Pitiphat W, Hung HC, Willett WC, Colditz GA, Douglass CW. Pulpal inflammation and incidence of coronary heart disease. J Endod 2006;32(2):99-103. [PubMed: 16427454]

28. Caplan DJ, Chasen JB, Krall EA, et al. Lesions of endodontic origin and risk of coronary heart disease. J Dent Res 2006;85(11):996-1000. [PubMed: 17062738]

29. Frisk F, Hakeberg M, Ahlqwist M, Bengtsson C. Endodontic variables and coronary heart disease. Acta Odontol Scand 2003;61(5):257-262. [PubMed: 14763775] 


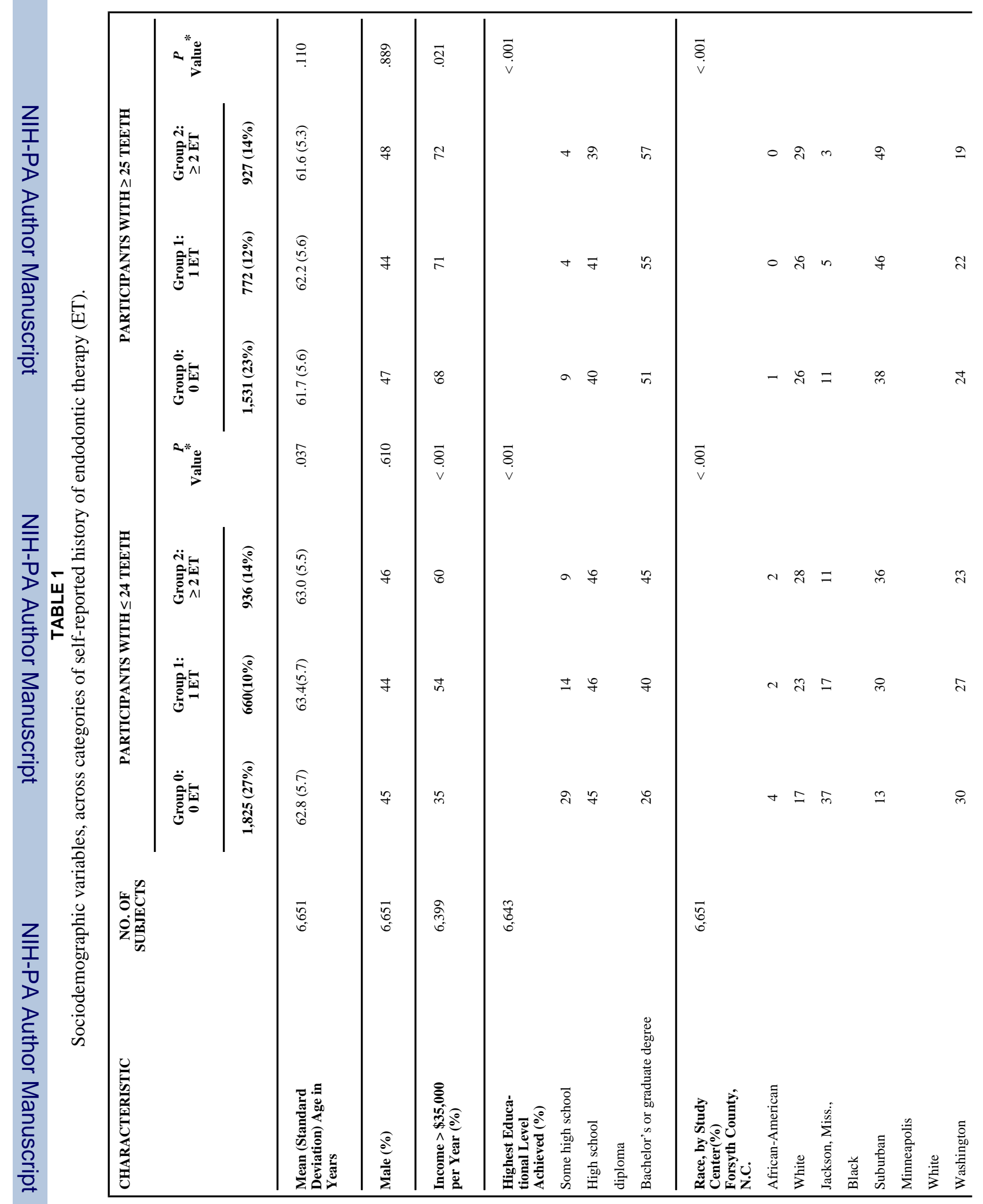

$J$ Am Dent Assoc. Author manuscript; available in PMC 2010 August 1. 


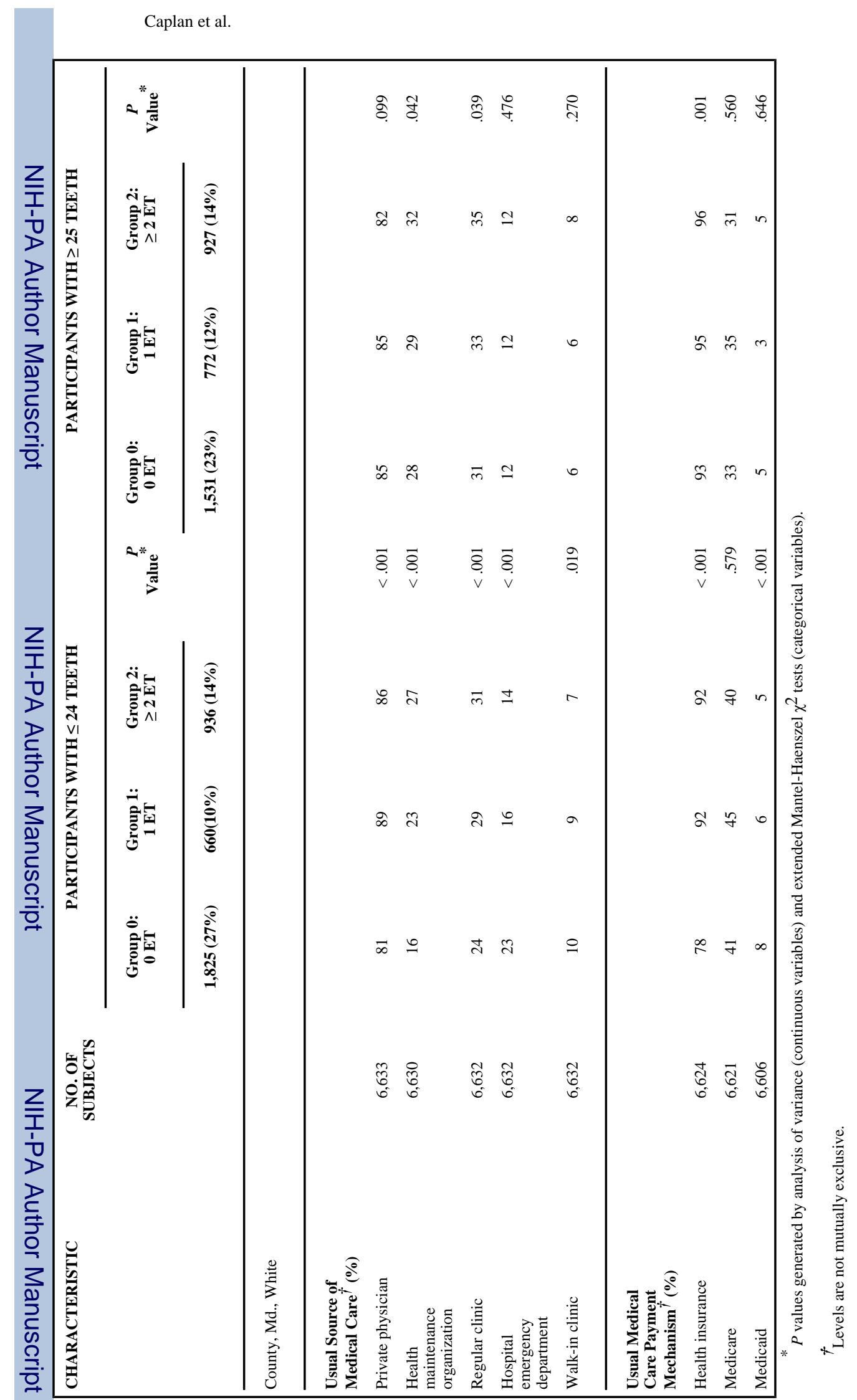

$J$ Am Dent Assoc. Author manuscript; available in PMC 2010 August 1. 


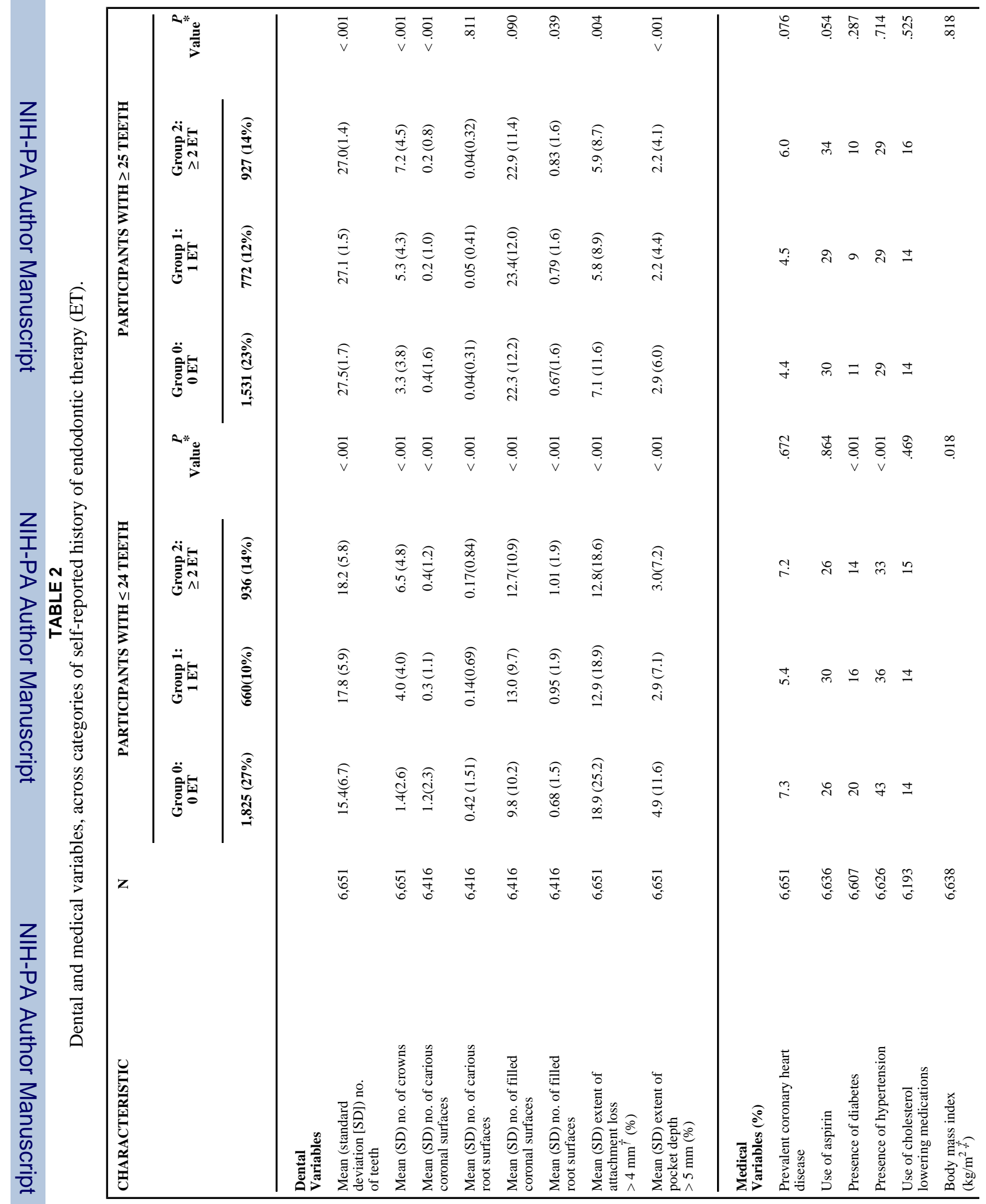




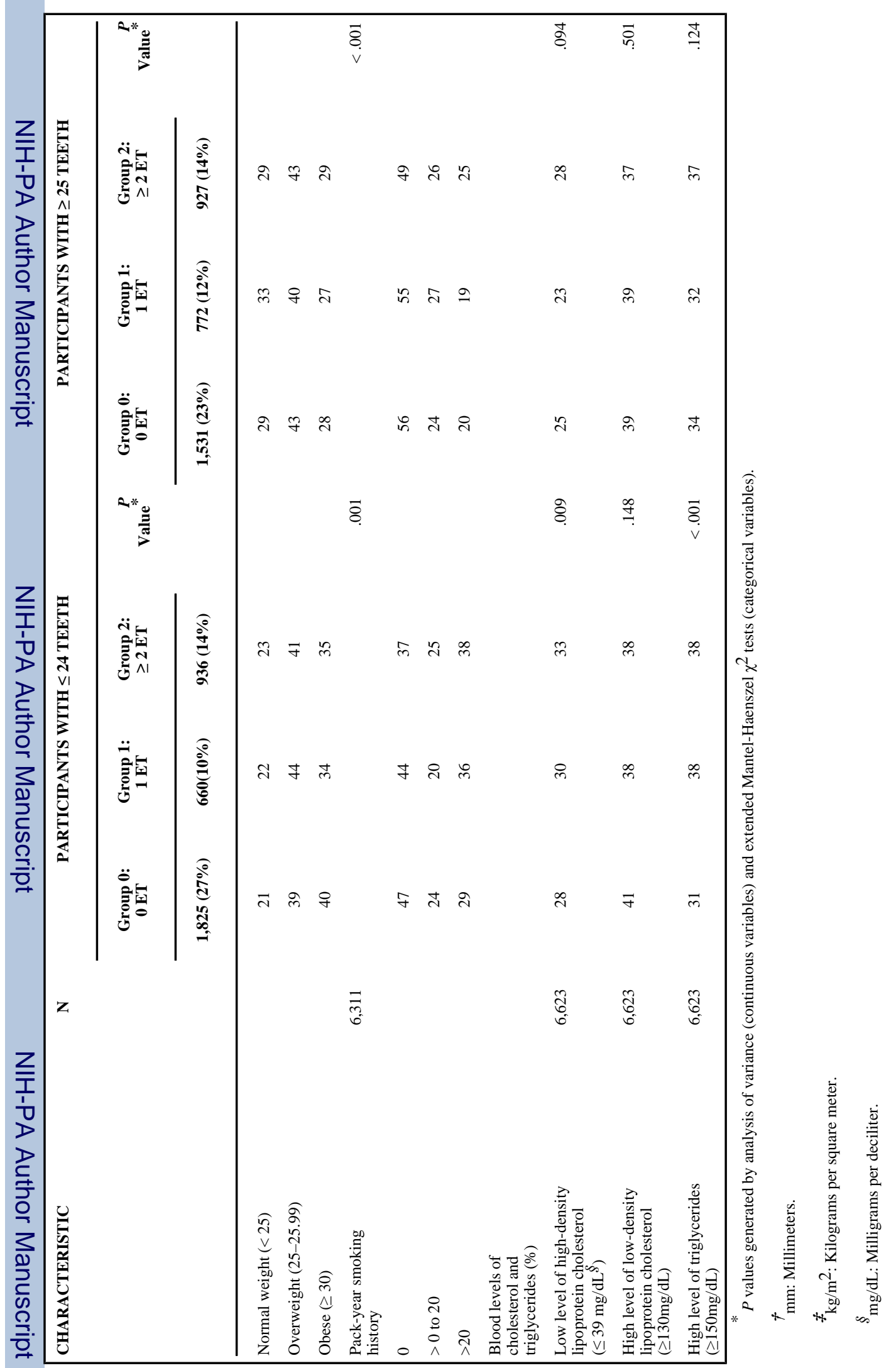

$J$ Am Dent Assoc. Author manuscript; available in PMC 2010 August 1. 
TABLE 3

Relationship between self-reported history of endodontic therapy (ET) and prevalence of coronary heart disease (CHD). ${ }^{*}$

\begin{tabular}{|c|c|c|c|}
\hline \multirow[t]{2}{*}{ VARIABLE } & \multicolumn{3}{|c|}{$\begin{array}{l}\text { RELATIONSHIP BETWEEN SELF-REPORTED HISTORY OF ET AND CHD } \\
\text { PREVALENCE (ODDS RATIOS [95\% CONFIDENCE INTERVAL]) }\end{array}$} \\
\hline & Initial Model & Full Model & Final Model \\
\hline Variables (No.) & 2 & 39 & 20 \\
\hline \multicolumn{4}{|l|}{ CHD Status (No.) } \\
\hline Participants with CHD & 395 & 326 & 339 \\
\hline Participants without CHD & 6,256 & 5,053 & 5,264 \\
\hline \multicolumn{4}{|l|}{$\begin{array}{l}\text { Self-Reported History of ET and No. of Teeth } \\
\text { (Odds Ratio [95\% Confidence Interval]) }\end{array}$} \\
\hline $0 \mathrm{ET}$ and $\geq 25$ teeth & Reference & Reference & Reference \\
\hline $1 \mathrm{ET}$ and $\geq 25$ teeth & $1.04(0.68-1.58)$ & $1.35(0.81-2.25)$ & $1.37(0.83-2.26)$ \\
\hline $2 \mathrm{ET}$ and $\geq 25$ teeth & $1.40(0.98-2.02)$ & $1.62(1.02-2.57)^{\dagger}$ & $1.62(1.04-2.53)^{\dagger}$ \\
\hline 0 ET and $\leq 24$ teeth & $1.73(1.28-2.34)^{\dagger}$ & $1.52(1.00-2.29)^{\dagger}$ & $1.55(1.05-2.30)^{\dagger}$ \\
\hline $1 \mathrm{ET}$ and $\leq 24$ teeth & $1.26(0.83-1.91)$ & $1.02(0.60-1.72)$ & $1.04(0.62-1.73)$ \\
\hline 2 ET and $\leq 24$ teeth & $1.68(1.19-2.39)^{\dagger}$ & $1.72(1.09-2.72)^{\dagger}$ & $1.74(1.12-2.69)^{\dagger}$ \\
\hline Age (in Years) & $-^{*}$ & $1.05(1.01-1.09)^{\dagger}$ & $1.04(1.02-1.07)^{\dagger}$ \\
\hline Sex (Male Versus Female) & - & $2.88(2.07-3.99)^{\dagger}$ & $2.93(2.16-3.96)^{\dagger}$ \\
\hline Income (> \$35,000 per Year) & - & $0.77(0.57-1.04)$ & - \\
\hline Education (Some High School, High School & - & $0.82(0.67-1.02)$ & $0.80(0.66-0.97)^{\dagger}$ \\
\hline
\end{tabular}

Race, by Study Center Versus Jackson, Miss.

Forsyth County, N.C.

\begin{tabular}{lll} 
African American & - & $2.50(0.98-6.39)$ \\
White & - & $1.59(0.86-2.95)$ \\
Suburban Minneapolis & - & $1.47(0.78-2.79)$ \\
Washington County, Md. & - & $1.30(0.73-2.33)$ \\
\hline Usual Source of Health Care & & \\
Private physician (yes/no) & - & $1.46(0.97-2.21)$ \\
Health maintenance organization (yes/no) & - & $1.04(0.76-1.44)$ \\
Regular clinic (yes/no) & - & $1.05(0.73-1.51)$ \\
Hospital emergency department (yes/no) & - & $1.71(1.24-2.37)^{\dagger}$ \\
Walk-in clinic (yes/no) & - & $1.40(0.86-2.28)$
\end{tabular}


VARIABLE

RELATIONSHIP BETWEEN SELF-REPORTED HISTORY OF ET AND CHD PREVALENCE (ODDS RATIOS [95\% CONFIDENCE INTERVAL])

(n)

Initial Mode

Full Model

Final Model

Usual Medical Care Payment Mechanism

Health insurance (yes/no)

Medicare (yes/no)

$-$

$-$

Medicaid (yes/no)

Dental Health

Crowns (0 vs. $\geq 1)$

Carious coronal surfaces $(0$ versus $\geq 1)$

Carious root surfaces ( 0 versus $\geq 1$ )

Filled coronal surfaces $(0$ versus $\geq 1)$

Filled root surfaces $(0$ versus $\geq 1)$

Extent of attachment loss $\geq 4 \mathrm{~mm}^{\S}(0$ versus $\geq 0)$

Extent of pocket depth $\geq 5 \mathrm{~mm}(0$ versus $\geq 0)$

Factors Associated With Coronary Heart

Disease

Aspirin use (yes/no)

Diabetes (yes/no)

Hypertension (yes/no)

Use of cholesterol-lowering medications (yes/no)

Overweight (versus normal weight)

Obese (versus normal weight)

Pack-year smoking ( $>0$ to 20 versus 0 )

Pack-year smoking (> 20 versus 0 )

Low level of high-density lipoprotein cholesterol

$\left(\leq 39\right.$ versus $\geq 40 \mathrm{mg} / \mathrm{dL}^{\mathscr{T}}$ )

High level of low-density lipoprotein cholesterol

$(\geq 130$ versus $\leq 129 \mathrm{mg} / \mathrm{dL})$

High triglycerides $(\geq 150$ versus $\leq 149 \mathrm{mg} / \mathrm{dL})$

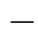

$-$

$-$

$-$

$-$

$-$

$-$
$1.28(0.75-2.17)$

$0.81(0.52-1.24)$

$1.45(0.92-2.30)$
$-$

$-$

$-$

\footnotetext{
* From multivariable logistic regression models.

${ }^{\dagger} P<.05$.

Dashes indicate data not applicable.

$\S_{\mathrm{mm}: \text { Millimeters. }}$

$\pi_{\mathrm{mg} / \mathrm{dL}: \text { Milligrams per deciliter. }}$
}

$\begin{array}{lcc} & 6.74(5.01-9.06)^{\dagger} & 6.55(4.92-8.71)^{\dagger} \\ - & 1.14(0.81-1.61) & - \\ - & 1.37(1.04-1.80)^{\dagger} & 1.30(1.01-1.69)^{\dagger} \\ - & 5.63(4.28-7.39)^{\dagger} & 5.17(4.00-6.69)^{\dagger} \\ - & 0.77(0.55-1.07) & - \\ - & 0.56(0.38-0.82)^{\dagger} & - \\ - & 0.92(0.64-1.32) & 0.92(0.65-1.31) \\ - & 1.61(1.18-2.20)^{\dagger} & 1.73(1.29-2.32)^{\dagger} \\ - & 1.55(1.15-2.08)^{\dagger} & 1.39(1.07-1.82)^{\dagger} \\ - & 1.08(0.82-1.42) & - \\ - & 0.82(0.61-1.09) & -\end{array}$

$1.88(1.33-2.64)^{\dagger}$

1.74(0.52-1.06)

-

$-$

$-$

$-$

0.94(0.69-1.27) -


TABLE 4

Relationship between self-reported history of endodontic therapy (ET) and prevalence of coronary heart disease, according to different reference categories.

\begin{tabular}{|c|c|c|c|}
\hline \multirow[t]{2}{*}{ REFERENCE } & \multicolumn{3}{|c|}{ HISTORY OF ET (ODDS RATIO [95 PERCENT CI ${ }^{\dagger}$ ]) } \\
\hline & Group 0: 0 ET & Group 1: 1 ET & Group 2: $\geq 2$ ET \\
\hline \multicolumn{4}{|c|}{0 ET and $\geq 25$ teeth } \\
\hline$\leq 24$ teeth & $1.55(1.05-2.30)^{t}$ & $1.04(0.62-1.73)$ & $1.74(1.12-2.69)^{\ddagger}$ \\
\hline$\geq 25$ teeth & Reference & $1.37(0.83-2.26)$ & $1.62(1.04-2.53)^{\frac{t}{*}}$ \\
\hline \multicolumn{4}{|c|}{$0 \mathrm{ET}$ and $\leq 24$ teeth } \\
\hline$\leq 24$ teeth & Reference & $0.67(0.41-1.09)$ & $1.12(0.74-1.70)$ \\
\hline$\geq 25$ teeth & $0.64(0.43-0.95)^{\frac{f}{t}}$ & $0.88(0.54-1.46)$ & $1.04(0.66-1.64)$ \\
\hline
\end{tabular}

